\title{
Un nido destrozado y sin relojes de cuerda. Alegorías didácticas del cambio climático
}

\author{
José Vico Martín \\ Escuela Internacional de Doctorado. Málaga. España.vico.martin@hotmail.com \\ ORCID: https://orcid.org/0000-0001-9554-5422
}

[Recibido: 21 diciembre 2020. Revisado: 8 enero 2021. Aceptado: 10 marzo 2021]

Resumen: Este artículo pretende retratar un mundo para proponer otro. Uno sabe que la ambición es grande, pero confía en que las probabilidades, aunque aún escasas, evolucionen a mejor. El retrato del mundo actual, el que nos está tocando vivir, podría perfectamente dibujarse con cualquiera de las varias alegorías con las que se ha representado el estado de pandemia en el que nos encontramos; una mascarilla, por ejemplo. Tanto hemos viajado por el mundo entero; tanto y a tantos hemos querido conocer; tan grandes han sido la masa y la velocidad del movimiento, que su creciente inercia y la fuerza de su arrastre, se ha llevado por delante al sentido de la prudencia: la virtud que Aristóteles, en su Moral a Nicómaco, atribuía al hombre que es en general el que sabe deliberar bien. Y para eso, para recuperar la correcta deliberación perdida, la educación se ha mostrado siempre como la mejor de las herramientas humanas. La defensa de la biosfera la hace ahora, además, especialmente necesaria. Dos alegorías más se han añadido aquí. Una para un esbozo del mundo actual: un nido destrozado y al borde de su inutilidad. La otra, como posibilidad de vuelta a la prudencia olvidada: la sustitución de los relojes eléctricos por los mecánicos de cuerda.

Palabras clave: Biosfera; Rachel Carson; Crisis ecológica; Autopoiesis; Deforestación: Homo suadens; Constructivismo educativo.

\section{A shattered nest with no mechanical clocks}

Abstract: This paper tries to portray a world to propose another. I know that the ambition is great, but I trust that the probabilities, although still slim, will evolve for the better. The portrait of the current world, the one in which we are living, could perfectly be drawn with any of the various allegories with which the pandemic state in which we find ourselves has been represented; a face mask, for example. We have travelled the whole world so much; so much and so many we have wanted to know; so great have been the mass and the speed of the movement, that its increasing inertia and the force of its dragging, has almost eliminated the sense of prudence: the virtue that Aristotle, in his Moral to Nicomacheus, attributed to man that it is generally the one who knows how to deliberate well. And for that, to recover the correct deliberation lost, education has always shown itself to be the best of human tools. The defense of the biosphere now makes it, furthermore, especially necessary. Two more allegories have been added here. One for a sketch of today's world: a shattered nest on the brink of worthlessness. And another as a possibility of returning to forgotten prudence: the replacement of electric clocks by mechanical ones

Keywords: Biosfere; Rachel Carson; Ecological crisis; Autopoiesis; Deforestation; Homo suadens; Educacional constructivism.

Para citar este artículo: Vico Martín, J. (2021) Un nido destrozado y sin relojes de cuerda. Alegorías didácticas del cambio climático. Revista de Educación Ambiental y Sostenibilidad 3(1), 1501. doi: 10.25267/Rev_educ_ambient_sostenibilidad.2021.v3.i1.1501

\section{Los antecedentes. Hechos preocupantes y reacciones tardías}

Este artículo arranca desde unos hechos reales. Quien lo escribe no es una persona joven y sus orígenes sociales son humildes. Está, por eso, acostumbrado a no tirar nada -a "reciclar", como se llama ahora a lo que se practicó toda la vida-, y a ser austero. Es un defensor convencido -y comprometido, hasta donde uno puede- en la 
urgente necesidad de un cambio importante en favor de unas relaciones biocéntricas del hombre con la naturaleza. Tiene nietos, tres, y teme que tengan que afrontar situaciones mucho peores a las que las que ya estamos padeciendo las dos últimas generaciones humanas.

Paralelamente y por desgracia, uno no tiene constancia de que la Historia de la Ecología figure entre las más sobresalientes disciplinas de la educación reglada española. Tampoco de la cultura popular. Prácticamente nadie, en el ámbito de la enseñanza y la divulgación, ha hecho justicia a los más sobresalientes personajes que, sin saber su importancia profética, aportaron sus ideas a la ciencia, a la filosofía, y la educación: Francisco de Asís, Vladimir Ivánovich Vernadsky, Teilhard de Chardin, Edouard Le Roy, Aldo Leopold, Henry David Thoreau, José Ferrater Mora, Rachel Carson...

De esta lista, incompleta por necesidad, la última, Rachel Carson, se adelantó a dar cuenta, en 1962 -o, al menos, fue la primera en documentarlo científicamente- de los estropicios que cierta revolución ("verde" se llamó, ingenuamente, a la lucha química contra las plagas), podía acabar produciendo en el mundo entero (Carson, 2010). No se le hizo caso, y hasta tuvo que soportar una dura y larga campaña pública en su contra.

Desde entonces, hemos vivido, hasta hoy, cincuenta y ocho años. Y, cuando esto se escribe -noviembre de 2020- la humanidad se encuentra en estado de pandemia por un ultramicroscópico virus del que, como todos sus parientes, ni siquiera sabemos si se puede clasificar como un ser vivo. Mira por dónde, aquella revolución "verde", que venía para salvar al mundo del hambre, no solo no ha logrado su objetivo, sino que su continuación, la tecnología digital (admirada hasta la idolatría por el mundo entero y objeto de potentes adicciones -sobre todo, por los jóvenes-) el "milagro" tecnocientífico, en el que tanto tiempo, esfuerzo y dinero se ha invertido -y ganado, por cierto- nos ha seguido apartando de lo que más debiera habernos importado: el exquisito cuidado de nuestra primera residencia, la biosfera. Estuvimos tanto tiempo discutiendo si los ladridos eran de galgos o de podencos que, por nuestra inmensa estulticia, hemos acabado siendo devorados por ellos. Debimos hacer caso a Tomás de Iriarte cuando ya en el año de 1782 remata esta discusión y nos dice al final de su conocida fábula Los dos conejos: "los que por cuestiones de poco momento dejan lo que importa, llévense este ejemplo"1 (p. 25).

Porque, de la conservación de nuestro sustrato natural, no nos hemos ocupado con la diligencia que era menester; $y$, en consecuencia, la salud biológica, psicológica y social humana está, ahora, en una fase de peligro extremo. Y eso que los "ladridos" se llevan escuchando, cada vez con mayor intensidad, desde hace ya bastantes años: En 1967, por ejemplo, Lynn Townsed White Jr., profesor de Historia Medieval en las universidades americanas de Princeton, Stanford y California, incluía una triste metáfora en su descripción de lo que ya estaba pasando como "Con la explosión demográfica, el cáncer de la urbanización no planificada, los depósitos geológicos de basura y desechos radiactivos, la verdad es que ninguna otra criatura ha manejado su nido tan mal en un tiempo tan corto como el hombre". (White, 2007, p. 80).

\footnotetext{
${ }^{1}$ Entendiendo "momento" en el sentido de trascendencia o peso, como quinta acepción de la RAE. Libro Fabulas Literarias de Tomás de Yriarte, localizables en https://es.wikisource.org/wiki/Los_dos_conejos
} 
No se pretende aquí, por supuesto, abominar, sin más, de los avances de las aplicaciones tecnológicas en medicina, cirugía y ciencias en general (aunque sea discutible el afán desmedido por la comodidad y por la prolongación de la vida más allá de ciertos límites naturales). De lo que se trata, en este momento, es de poner de manifiesto una colosal y estúpida soberbia: nos habíamos creído en la cima del desarrollo de la ciencia y del bienestar económico -aunque, eso sí, solo para los países ricos- $y$, por una pavorosa pérdida de conciencia naturalista e histórica, un diminuto agregado de proteínas nos pone "patas arriba" el mundo entero. ¿Para cuándo se deja, como se echaba de menos más arriba, el estudio de la historia de la ecología entre la más sobresaliente de las disciplinas de la educación reglada española? ¿Cuántos ladridos más habrán de sonar para que, de una vez por todas, abandonemos nuestras acomodaticias vidas?

Por lo mismo, por pura indolencia, a Rachel Carson, cuando comprobó experimentalmente (era bióloga y ejercía como tal en el Administración de Pesca y Vida Salvaje de los Estados Unidos de América) los efectos destructivos de la expansión del uso del DDT, casi nadie le hizo caso. Primavera silenciosa -el que debiera ser libro de obligada lectura en todas las escuelas- hace, precisamente, referencia al estremecedor silencio de los campos por la muerte masiva de los pájaros de su región. Mientras, los insectos, los únicos y oportunistas beneficiarios de tal circunstancia, "aprendieron" a generar resistencia al tóxico ¡Gran éxito intelectual el nuestro!

Como en tantos otros momentos de la historia del hombre, en nuestra relación con la naturaleza y durante muchos años, hemos funcionado en modo de ensayo y error. Solo a medida que las tristes consecuencias de nuestros actos se han ido haciendo cada día más patentes, hemos caído en la cuenta -y todavía con muchas reticencias- de nuestros graves errores. Durante siglos, hemos cantado y bailado como las insensatas cigarras, para que ahora, deprisa y corriendo, tengamos que aprendernos el papel de las previsoras hormigas. Tuvimos tan aletargada nuestra capacidad intelectual y anticipatoria, entonces, que vamos a tener que despertarla, ahora, poniendo a trabajar, a pleno rendimiento, nuestra mejor herramienta: la razón. Pero no, desde luego, la vieja razón, pacata, egoísta, parcelada y utilitaria a la que nos hemos ido acostumbrando desde la Revolución Industrial, sino otra muy distinta; una razón nueva, biocéntrica, de largo alcance existencial y temporal, mucho más inteligente y, sobre todo, imbricada al máximo con la totalidad de la naturaleza, de la que dependemos por nuestro linaje común. Una razón, en suma, que sea capaz de "ver" mucho más allá de nuestra capitalista subjetividad material; que se trascienda a sí misma, y que busque su lugar, no en nuestros limitados cuerpos y bagajes, sino en la continuidad universal de la vida. Una razón, en suma, guiada por un pensamiento complejo. El de Commoner (1978, p. 26), por ejemplo:

[...] ¿cómo podemos englobar en una idea unificadora la existencia como entidad continua y estable, del ambiente caleidoscópico y ricamente poblado de una selva tropical y la de un desierto aparentemente e inmutable?; [...] ¿qué rasgos comunes pueden explicar el comportamiento ambiental de una rata, un halcón, una trucha, una lombriz, una hormiga, las bacterias del intestino humano, o las algas que dan el color verde al lago Erie?

[...] Cada una de estas maneras diferentes de considerar el sistema del medio ambiente no es más que la visión de un estrecho sector del 
complejo total [...y] como cada una de ellas solo puede iluminar algunos rasgos del conjunto, la imagen obtenida tiene que ser necesariamente falsa hasta cierto punto.

[...] No obstante, en el mundo real, todo lo que existe en el medio ambiente está relacionado con todo lo demás. (La cursiva es nuestra).

El resalte de la cursiva del último de estos párrafos, obedece a que lo que en él se predica es, nada menos, que la primera de las cuatro Leyes de la Ecología. La base natural de lo que hoy llamamos el "pensamiento complejo".

Si la humanidad, en consecuencia, no es capaz de aplicar un cambio drástico a su educación; si no resituamos en su justo lugar -el de herramienta limitada, reformable y a escala humana- al arsenal científico y tecnológico que ha conseguido abducir nuestras voluntades; si eso no se logra a través de concepciones sistemáticas, emergentistas e inestables del mundo que nos rodea; y si no lo hacemos en poco tiempo, la alienación del Homo sapiens y la dependencia tiránica de las máquinas acabarán del todo con la naturaleza, con las artes y, lo que es peor: con el espíritu de curiosidad y de respeto sobre el fenómeno humano.

Pocos, muy pocos, son conscientes de la infinita complejidad estructural y organizativa de una lechuga sobre un moderno ordenador. Y la afirmación no es retórica: aún recuerdo las risitas de mis alumnos de informática en una clase de bachillerato oyéndome decir semejante "disparate". Es lógico: la mayoría de ellos están al corriente y dominan a la perfección los teclados, los bits, los gigas, los bucles y las comunicaciones online. Pero pocos, muy pocos, han visto sembrar su minúscula semilla; la han visto germinar y crecer poco a poco, producir pequeñas y bonitas flores blancas, ser fecundadas por las abejas, producir nuevas semillas; y morir, por fin, cumplida su misión en el ciclo interminable de la vida. Guardadas convenientemente, o dispersadas por el viento, volverán a ser capaces de reiniciar, otra vez, -si nosotros las dejamos- el mismo viaje circular. Y, así, llevan millones de años en un interminable proceso de conservación de la vida, la autopoiesis. Eso, que se viola constantemente cuando se retiran las hojas caídas de los árboles, en lugar de dejarlas a la descomposición natural, necesaria para la copia autopoiética de nuevos árboles. Eso, que es nada menos que la regeneración bioquímica de toda la naturaleza, debería enseñarse como el primer principio de la epistemología aplicada a la educación. ¿Qué máquina artificial aguantaría un viaje ininterrumpido como el de la humilde lechuga? Mis alumnos de informática, ese día no entendieron nada. Nadie -ni siquiera sus familias- les había transmitido ninguna emoción ante semejante maravilla del funcionamiento de la biosfera: la autoreproducción interminable. Toda una lástima.

Por desgracia, de una inmensa cantidad de cosas, los jóvenes de hoy, no saben de su existencia más allá del "super". Por eso, la naturalización de la enseñanza, su aplicación no más allá de la escala de las necesidades vitales humanas, y la vuelta a los relojes de cuerda es inaplazable. ${ }^{2}$

Pido disculpa por esta breve digresión, debida al impacto psicológico que a uno le produce contemplar a unos ególatras políticos completamente desnortados, y a una

\footnotetext{
${ }^{2}$ Este articulista, para poner de manifiesto la utilidad de la energía limpia sobre la química de las pilas y baterías, mostró a un grupo de alumnos de bachillerato, un reloj de pulsera de cuerda, explicando su funcionamiento. Solo uno de ellos sabía, por su abuelo, de la existencia de tales "artilugios".
} 
ciudadanía alienada, asustada y enmascarada incluso en espacios abiertos y solitarios, y convencidos, eso sí, de que esto lo arregla una vacuna que les han prometido que está al llegar. De modo que, los unos y los otros podemos estar tranquilos: dentro de poco seguiremos pudiendo comprar nuevos viajes y utilizar sin recato automóviles -con aire acondicionado, faltaría más- trenes, barcos y aviones. Una nueva lección de "inteligencia humana". Y una muestra más de que, la "comodidad" de la obediencia, se suele imponer, casi siempre, a la incertidumbre de la libertad.

Digamos, en cualquier caso, tristemente y no como disculpa a los hechos preocupantes sino como ejemplo de mal hacer, que esto no es nada nuevo. Valga añadir, al efecto, que, aun con menor proporción que ahora, la historia del ecologismo está plagada de otros ilustrativos ejemplos de la estupidez humana. Muchos de ellos, bastante lejanos; como este, referido a las desnudas y secas montañas del Ática, detrás de la Acrópolis:

En los siglos que precedieron a la Edad de Oro de Atenas, esas montañas se hallaban cubiertas de bosques y eran regadas por manantiales y arroyos. El filósofo Platón vio ya muestras de los cambios ocurridos poco antes: [...] aún había en Atenas edificios hechos con vigas de árboles provenientes de las laderas que en los días de este filósofo ya estaban erosionadas y cubiertas sólo de hierba, y él mismo visitó templos que alguna vez estuvieron dedicados a los espíritus guardianes de manantiales que, para entonces, ya se habían secado. (Platón, Critón 111 B-D, Citado en Hughes,1981, p. 15).

Y, ¿por qué tendría que haber templos que alguna vez estuvieron dedicados a los "espíritus guardianes de manantiales"? La eterna existencia de la degradación provocada por el hombre parece la respuesta más probable.

También hay, cansinamente, otros ejemplos mucho más cercanos (Guerrero, 2014):

[...] En el municipio de Soba (Cantabria), se encuentra una de las infraestructuras más impresionantes construidas en el siglo XVIII para abastecer a la Armada española. Lo llaman el Resbaladero de Troncos [...]. Su destino eran las Reales Fábricas de Liérganes y La Cavada, donde se producían cañones, piezas de artillería y munición. [...] En el siglo XVIII se construyeron en esas fábricas casi 3.000 cañones con los que se armaron decenas de navíos, fragatas y galeones. Es un ejemplo de la masiva deforestación que sufrió la montaña pasiega durante los siglos XVI, XVII y XVIII. El balance: 10 millones de árboles talados y 50.000 hectáreas de bosque arrasado.

Y bastantes más que siguen, cómo no, en pleno siglo XXI. Como estos otros dos:

Después de meses de calor extremo y sequía en Australia, finalmente llegaron los incendios. Australia experimenta incendios forestales cada año. Pero este año son particularmente extremos, y el verano en el hemisferio sur acaba de comenzar. Según la evaluación preliminar de los incendios, ocho millones de hectáreas han sido destruidas por las llamas hasta el momento. Veinticinco personas y millones de 
animales han muerto. Regiones enteras se han quedado sin energía y las nubes de humo ahora cubren la mitad del continente.

Pero Australia no es el único lugar en llamas. En 2019, la plataforma en línea Global Forest Watch Fires (GFW Fires) contó más de 4,5 millones de incendios en todo el mundo que fueron mayores de un kilómetro cuadrado. Eso es un total de 400.000 incendios más que en 2018. "El número de incendios y su tamaño varían de año en año, pero la gran tendencia es que el riesgo de incendio aumenta a nivel mundial", dijo DW Susanne Winter, gerente del Programa Forestal de WWF en Alemania.

Las razones por las cuales los incendios comienzan y se establecen en principio son complejas. Pero los expertos ahora apuntan a una conexión entre el creciente número de incendios y las temperaturas oceánicas más cálidas como resultado del cambio climático (Schauenberg, 2020).

Y, como afirmaba Wilson (2007, p. 121):

[...] cada año, se quema un 5\% de la superficie terrestre, en su mayor parte para crear nuevos campos cultivables o fertilizar los antiguos. Todos estos métodos sobrecargan la atmósfera con gases de invernadero en cantidad suficiente para desequilibrar el clima del planeta entero.

Sin intención de exhaustividad, en lugar de emplear valiosos recursos mentales a la inútil tarea de dividir polinomios, valdría la pena invitar al alumnado de la ESO a hacer un sencillo cálculo basado en los datos de esta cita y que permite hacer una apreciación mucho más significativa de las consecuencias de un "inocente" 5\%: Cuatro millones y medio de incendios de más de un kilómetro cuadrado equivalen a unos cinco millones de kilómetros cuadrados; o sea, diez veces la superficie total de España. Y eso, como mínimo, y un año detrás de otro. No es de extrañar que, en 2007, Wilson calificara estos hechos como capaces de desequilibrar el clima del planeta entero.

\section{Y, ¿por qué somos así? La lógica del aprendizaje social}

En su libro de 2008 ¿Quién teme a la naturaleza humana? Homo suadens y el bienestar en la cultura: biología evolutiva, metafísica y ciencias sociales de Castro Nogueira et al., se puede leer esto:

La socialidad característicamente humana, esa microsocialidad emocionalmente intensa en cuya mecánica suadens descansan nuestros sistemas de creencias, nuestras filias y fobias y nuestro mundo de sentido, teje en torno a cada individuo una burbuja de experiencia inmunizadora, un auténtico invernadero emocional y doctrinal que se erige como espacio de reposo, sosiego y sentido. Es desde el interior de esos espacios microsociales, desde su socioquímica particular, su clima emocional, sus figuras, sus apegos y desapegos, desde donde el individuo contempla el mundo, hace juicios de valor, toma decisiones y evalúa su comportamiento (Castro Nogueira et al., 2008, p. 370) 
Y, desde ahí, la cuestión es inevitable: ¿Qué es el Homo suadens y por qué se doblega ante esa mecánica emocional descrita? La respuesta tendría que descansar, lógicamente, en la potencia del aprendizaje -assessor, lo llaman sus autores- que le ha conducido a tal estado de sumisión. Porque, si uno consulta su etimología, resulta que el vocablo 'suadens' tiene su origen en el verbo 'suadere' (persuadir), de cuyo participio deriva 'persuasivo'. Así que, entonces, el Homo suadens es el "hombre persuasivo", el que trata de orientar (de ahí lo de assessor) a otro para que adopte ciertas ideas o acciones. Y, si se presta gustoso a interpretar ese papel, es porque también él aprendió por persuasión activa.

Lo que resume, con desnuda claridad, el corolario original de sus autores: "La lógica del aprendizaje assessor funciona de modo que se admite como verdadero lo que se transmite como tal, sin necesidad de contrastarlo" (Castro et al., 2013).

Aludiendo, entonces, a las propias vivencias sobre semejante afirmación, uno puede plantearse lo siguiente: Ahora bien, ¿qué pasa si, en muy poco tiempo, se producen tan intensos cambios políticos y culturales que sean capaces de alterar (y añado, ahora, "exagerada, malintencionadamente, o ambas cosas a la vez") el mecanismo assessor y condicionar, así, la vida social misma?

La fuente original ofrece una mayor precisión:

El aprendizaje depende de dos funciones cerebrales: la categorización perceptiva y la memoria. La categorización perceptiva es necesaria para la memoria, la cual trabaja en definitiva sobre categorizaciones previas. La categorización perceptiva y la memoria son necesarias, pero no son en conjunto suficientes para que el aprendizaje se produzca. Es precisa, además, la presencia de estructuras cerebrales que generen asimetrías de valor entre las conductas a medida que se ponen a prueba y que sirvan de guía para escoger cuál es apropiada para el organismo en una situación dada (Castro Nogueira et al., 2008, p.136).

\section{Lo que pudo haber sido, y no fue}

Queda dicho antes que, cuando esto se escribe, nos encontramos en España y en final del año 2020. Queda también escrita la intencionalidad educativa de este trabajo. La edad, y la profesión principal, además, de este autor, le permiten recordar con bastante precisión hechos político-sociales vividos desde hace más de cincuenta años. Por ejemplo, la Ley General de Educación de 1970; la que estableció la obligatoriedad de la enseñanza hasta los catorce años y la estructura fundamental de lo que se llamó Educación General Básica, a la que se vincularía una Formación Profesional de Primer grado, que no estaba, hasta entonces, ligada al sistema educativo previo. La vigencia de la EGB (hasta 1990), fue la más larga desde su creación hasta hoy: veinte años. Le seguirían, en los otros treinta, hasta 2020, otras seis leyes educativas más. 0 sea, a una media de cinco años por ley. Casi una distinta por legislatura. Y, ante semejante derroche normativo, económico, político y social; la duda es pertinente. ¿Han sido objetivamente justificables tantos cambios?, ¿aumentó, de forma proporcional y ostensible, la eficiencia de la educación española en este período?, ¿se evaluaron, con serios fundamentos pedagógicos, los resultados de cada variante legal, antes de 
sustituirla por otra?, ¿cuáles fueron las reacciones de sus receptores y cuáles las de sus ejecutores cuando, sin apenas tiempo de adaptarse bien a una, se la sustituía por otra?, ¿se tuvo suficientemente en cuenta la experiencia de los docentes?

Uno cree honestamente que, los unos y los otros, hemos estado mirando hacia otro lado mientras contemplábamos tamaños disparates. Claro que una estructuración territorial y política como la de la España de este período, lo que menos auspiciaba era, precisamente, la coherencia y la solidaridad internas en todos los órdenes.

No es, desde luego, la intención de este trabajo analizar con detalle cada una de las siete leyes educativas de la democracia española ni sus estructuras políticas ni territoriales; pero sí se quiere situar en su contexto político-social una crítica constructiva a la persistencia en nuestra educación -la reglada y las demás- hacia resultados práctico-económicos coyunturales primordialmente, y en asegurar, después, cuantas más parcelas político-identitarias mejor. Cuando, lo que hubiera sido deseable y necesario desde la década de los setenta en lugar de lo hecho, sería dotarse de un amplio soporte eco-educativo centrado en la transmisión de valores y sistemas cognitivos de pensamiento complejo, sistemático, naturalista y ético-social.

\section{Algunas consecuencias lógicas y deontológicas}

Es conocido el hecho de que todo recuerdo sugiere nuevas reflexiones. y las anteriores remembranzas no son una excepción.

Vivo en un país rico. He sido, como queda dicho, profesor en la Educación Secundaria $y$, desde hace años, cultivo un pequeño huerto familiar. Mi visión de la unidad ontológica de la naturaleza y de su continuidad funcional ha ido afirmándose -hasta pudiera ser que como penúltima reacción de rebeldía juvenil- hacia una "categorización perceptiva" cada vez más abarcadora, al ver cómo la población en general se dejaba arrastrar por una cultura de consumismo compulsivo que, sin ningún disimulo, y parafraseando la preocupante afirmación de los hermanos Castro en Castro et al. (2013) [admitía] como verdadero lo que se [transmitía] como tal, sin necesidad de contrastarlo.

Valga señalar, en este sentido y como justificación a los cuatro apuntes biográficos ofrecidos, la cantidad de veces que, durante muchos años, este antiguo profesor ha tratado de revertir los efectos educativos de semejante sentencia. Y la cantidad de veces, además, en las que he echado en falta en la educación española aquella "presencia de estructuras cerebrales que generen asimetrías de valor entre las conductas a medida que se ponen a prueba y que sirvan de guía para escoger cuál es apropiada para el organismo en una situación dada" (Castro Nogueira et al., 2008, p.136):

El paralelismo de esas concepciones antropológicas y cognitivas de los profesores Castro Nogueira con el constructivismo educativo y su desarrollo fáctico, siempre personal -aunque pocas veces institucional y social- mediante el aprendizaje significativo, es tan evidente, que las consecuencias lógicas y deontológicas de todo esto, para quien dispone de tiempo, tiene descendientes, desea mantener crítico su intelecto y conoce de primera mano el colosal estropicio educativo que estamos provocando, le surge por sí sola una reacción natural: ceder a alguien, una alternativa naturalista del conocimiento -ensayada durante años por quien esto escribe- y una 
transmisión del mismo que utilice la razón ecológica universal -la autopoiesis intelectiva- en lugar de la simple persuasión assesor. Un aprendizaje fundamentado, en suma, en la imbricación de las imágenes y representaciones mentales que los fenómenos observados nos provocan, con la constitución neuronal y las vivencias propias de cada sujeto. Y, eso, extendido a la totalidad de la biosfera.

Habrá tiempo -pero siempre desde ahí- para reeducar también los procesos de abstracción y formalización propios del conocimiento científico para hacerlos más vitales. Pero, antes que eso, es necesario devolver a nuestra especie a la regulación homeostática cultural de los sistemas humanos, secularmente ensayada por la evolución geobiológica. La siguiente afirmación es una muestra de esa necesidad.

Para el hombre de la calle la mayoría de las versiones que suministran la ciencia, el arte o la percepción difieren de formas distintas del mundo familiar del que él se sirve y que él mismo ha construido en un bricolaje barato a partir de diversos fragmentos de las tradiciones científica y artística y desde su propia lucha por la supervivencia. Ciertamente este es el mundo que suele darse por real, pues la realidad de un mundo, al igual que acontece con el realismo de una pintura, es en gran medida una cuestión de hábitos (Goodman, 2013, p. 41).

Una mirada, además, mínimamente atenta al mundo actual, delata, de inmediato, la concordancia práctica de las aseveraciones de un filósofo relativista americano, Nelson Goodman, con los tres hermanos españoles Castro Nogueira: un biólogo, un sociólogo y un filósofo. Los cuatro, con importantes repercusiones sobre el mundo de la educación. Aunque hay, sin embargo, una significativa diferencia generacional. Mientras que la publicación inicial de Goodman fue en 1978; la primera edición de ¿Quién teme a la naturaleza humana? aparecía en el año 2008. Los treinta años transcurridos no han sido inocuos. Tampoco, en el contexto de la educación reglada y popular española.

La continuidad de las tradiciones científica y cultural, los hábitos familiares y hasta la propia lucha por la supervivencia como dice Goodman (2013); todas esas componentes del mundo de 1978, se han desmenuzado en un bricolaje más barato que nunca. Lo que, en coherencia con los autores en los que se basa la argumentación en marcha, ha terminado cristalizando, a partir de 2008, en una versión social completamente alocada.

Ahora mismo, cuando se transcribe la cita anterior y como queda dicho, el planeta entero está padeciendo los efectos de la expansión de un coronavirus. Circunstancia, esta, que puede perfectamente exhibirse como ejemplo, una de las muchas "versiones" válidas que podrían definir "un mundo": una circunstancia diferenciada en el tiempo, en un dominio concreto, y ampliamente generalizada. En nuestro caso, una población terrestre, desprevenida, asustada y desnortada por los múltiples efectos de uno cualquiera de los millones de microorganismos que habitan la Tierra ${ }^{2}$. Precariedad humana provocada por nuestro antiguo y mal hacer generalizado.

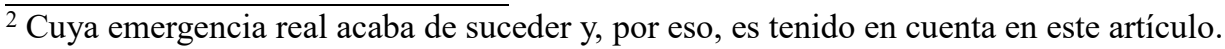




\section{Referencias}

Carson, R. (2010). Primavera silenciosa. Barcelona: Editorial Crítica, S.L.

Castro Nogueira, L., Castro Nogueira, L. A., \& Castro Nogueira, M. A. (2008). ¿Quién teme a la naturaleza humana? Homo suadens y el bienestar en la cultura: biología evolutiva, metafísica y ciencias sociales. Madrid: Editorial Tecnos.

Castro, L., Castro, L., Castro, M. A., \& Toro, M. A. (2013) Cultura, adaptación y ciencias sociales: una aproximación naturalista. Contrastes. Revista Internacional de Filosofía: Suplemento (18), 239-254. https://doi.org/10.24310/Contrastescontrastes.v0i0.1170

Commoner, B. (1978). El círculo que se cierra. Esplugues de Llobregat, Barcelona: Plaza \& Janés, S. A.

Goodman, N. (2013). Maneras de hacer mundos. Madrid: Machado Grupo de Distribución, S. L.

Guerrero, T. $(29,10,2014)$. La salvación del bosque que arrasó la Armada española. El Mundo

Hughes, J. D. (1981). La ecología de las civilizaciones antiguas. México D. F., México: Fondo de Cultura Económica.

Schauenberg, T. $(9,1,2020)$. Incendios forestales: el cambio climático y la deforestación aumentan el riesgo global. Deutsche Welle (DW Español)

White Jr., L. (2007). Raíces históricas de nuestra crisis ecológica. Revista Ambiente y Desarrollo 23(1), 78-86.

Wilson, E. O. (2007). La Creación. Salvemos la vida en la Tierra. Madrid: Katz Editores. 